\title{
Research to photovoltaic MPPT control strategy based on improved conductance increment method
}

\author{
Huaizhong Chen ${ }^{\mathrm{a}}$ \\ Zhejiang Industry Poiytechnic College, Shaoxing, China
}

\begin{abstract}
The output power of the photovoltaic is a kind of nonlinear function which is influenced by the intensity of sunlight and internal junction temperature. In the external environment stable situation, photovoltaic, the component exists only the maximum power output point. This paper analyzes the output characteristics of solar photovoltaic array and the advantages and disadvantages of MPPT method, and put forward a kind of improved conductance increment method on this basis. The improved conductance increment method combines the traditional conductance increment method and the constant voltage tacking method. The system is able to steadily and fast track the maximum power point and the result owns high tracking precision. Under various situations, especially the adverse situation in which the sunlight changes suddenly and so on, it has high adaptive ability and can realize the maximum power point tracking to the photovoltaic cell.
\end{abstract}

Keywords: photovoltaic array; maximum power point tracking (MPPT); conductance increment method.

\section{Introduction}

The solar energy is the major renewable and clean energy. The frequently-used solar photovoltaic cell is mainly the silicon solar cell. Under the influence of temperature and sunlight, the output power presents a nonlinear characteristic. As the output characteristics are largely influenced by the factors such as sunlight and temperature, thus the solar cell itself is an instable power source. In order to improve the stability and efficiency of the generation, researching a kind of high-efficiency algorithm for the maximum power output is of great significance. MPPT makes the cell array can intelligently control and output the maximum power under the environment with low temperature and intensity of illumination by controlling the voltage output at the end of solar array. At present, the frequently-used MPPT method includes conductance increment method, perturbation and observation method, etc. These algorithms are simple in structure and easy to be realized, but they also have some shortages. For example, the disturbance around the maximum power point is large, and it is influenced by the environment, and the robustness is poor, etc. To solve the problems above, a kind of MPPT control method based on the improved conductance increment has been put forward in this article [1-3].

\footnotetext{
${ }^{\text {a } C o r r e s p o n d i n g ~ a u t h o r ~: ~ c h z 702 @ 163 . c o m ~}$
} 


\section{Photovoltaic MPPT control system}

\subsection{The equivalent model of photovoltaic cell}

In Fig.1, it is about the equivalent model of photovoltaic cell. It is composed of ideal current source Is, anti-parallel diode $\mathrm{D}$, series resistance Rs and the parallel resistance Rsh. Among them, the Is value is equal to the value of the cells' short-circuit current; its size reflects the sunlight intensity of the environment where the photovoltaic cell is located [4-5].

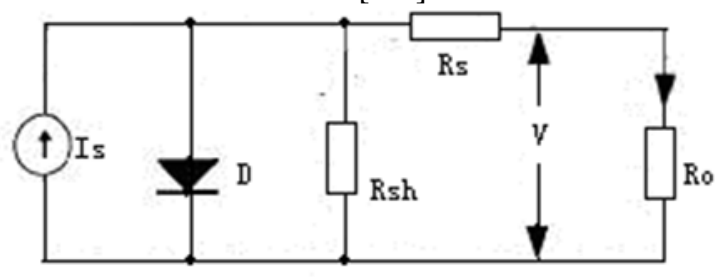

Figure 1. Equivalent model of photovoltaic cells

The formula below is a relation equation between the characteristics of I and V in photovoltaic cell:

$$
I=I_{s}-I_{o}\left[\exp \left[\frac{q\left(V+R_{S} I\right)}{A K T}\right]-1\right]-\frac{q\left(V+R_{S} I\right)}{R_{s h}}
$$

Under ideal situation, Rs can be approximate to zero, and Rsh is approximate to infinity, then the formula above can be simplified as:

$$
I=I_{s}-I_{o}\left[\exp \left[\frac{q\left(V+R_{S} I\right)}{A K T}\right]-1\right]
$$

In the formula, I is working current; Io is reverse saturation current; V is the output voltage of cell, the others are content. Thus, the output power of photovoltaic cell is:

$$
P=I_{s} \cdot V-I_{o} \cdot V\left\{\exp \left[\frac{q}{A K T}\right]-1\right\}
$$

It shows that the output power of photovoltaic cell is in a nonlinear function between the sunlight intensity and temperature, but it is in a proportional relation with the current and voltage.

\subsection{PV output characteristics}

The Fig. 2 is about an output characteristic curve of photovoltaic cell. In the figure, it is a V-I output characteristic curve and a V-P output characteristic curve [6].

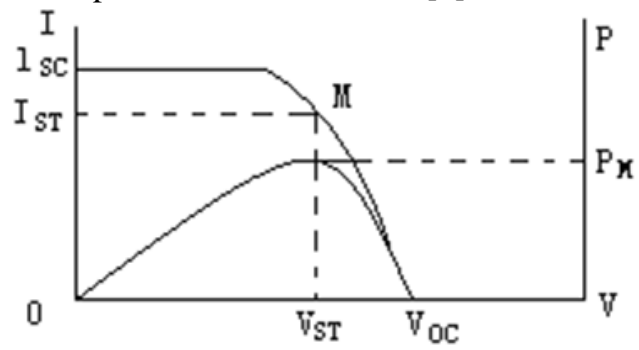

Figure 2. Output characteristics of photovoltaic cells 
From this figure, it can be seen that the output characteristic curve of photovoltaic cell owns nonlinearity. The V-P curve of photovoltaic cell is approximate to a parabola. There is a unique point $\mathrm{M}$ on the V-P curve; this point is the maximum power operating point $\left(\mathrm{V}_{\mathrm{M}}, \mathrm{P}_{\mathrm{M}}\right)$. At this time, the corresponding optimal current is $\mathrm{I}_{\mathrm{M}}$. In the actual application, the output power of photovoltaic cell will change along with the variation of environment temperature and illumination. The photovoltaic cell, as the basic generation unit of solar photovoltaic power generation system, is easy to be influenced by the surrounding buildings, trees, telegraph poles and the dark clouds in sky, etc. The influence on the output characteristics of photovoltaic cell by the partial shade is as shown in Figure 3.

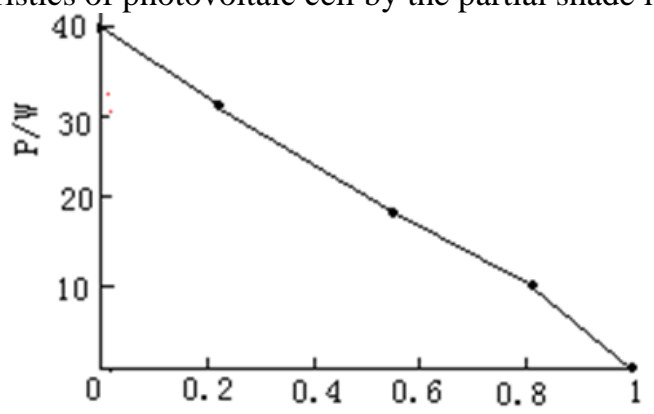

Figure 3. Output characteristics by the partial shade

From this figure, it can be seen that the maximum power point decreases along with the increase of shading proportion; the shade has an obvious influence on the output characteristics.

\section{Improving the photovoltaic MPPT control method}

\subsection{Constant Voltage Tracking Method}

The basic thoughts of constant voltage tracking (CVT) method is to control the output voltage of photovoltaic cell at a fixed place. The output voltages of photovoltaic arrays are all distributed around this voltage. At this time, the photovoltaic array approximately works at the maximum power point. The CVT method is simple in design idea and structure. It is easy to be controlled and realized with high reliability and stability. However, there is a great limitation existing in the application. It ignores the influence on the open-circuit voltage of photovoltaic cell by the environment temperature. In the actual situation, the external temperature is impossible to be kept constant, so the control precision is poor and the CVT method can't really realize the maximum power point tracking on the photovoltaic array. Only in the application scenario where the variations of sunlight intensity and temperature are slow and the ranges are small can the corresponding voltage value at the maximum power point be relatively constant[7-8].

\subsection{Conductance Increment Method}

The conductance increment method realizes the maximum power point tracking in the method of comparing the instant admittance of photovoltaic array with the variable quantity of admittance. The following control law can be obtained:

$$
\begin{gathered}
P=U I \\
\frac{d P_{\max }}{d U}=I+U \frac{d I}{d U}=0
\end{gathered}
$$




$$
\frac{d I}{d U}=-\frac{I}{U}
$$

The conductance increment method has many merits. When that the variable quantity of output conductance is equal to the negative value of output conductance is satisfied, the solar panel works at the maximum power point. When the sum between the conductance increment of solar panel and the instant conductance is bigger than zero, the working voltage of solar panel shall be increased to make it reach the maximum power point. When the sum between the conductance increment and the instant conductance is smaller than zero, the working voltage shall be decreased to make it reach the maximum power point. The conductance increment method is the most frequently-used control method for the maximum power point, but the external environment has a great influence to the algorithm, which makes the system oscillate at the maximum power point and leads to the serious loss of power[9].

\subsection{Improvement of MPPT Algorithm}

In this article, based on the frequently-used control algorithm for the maximum power point tracking and combing the CVT method with the conductance increment method, it put forward a control algorithm that can quickly respond to the environment variation, effectively control the oscillation at the maximum power point, and improve the tracking efficiency. In other words, it is a MPPT control algorithm combing the CVT method and the conductance increment method. The MPPT control method is realized mainly by controlling the duty ratio of DC-DC convertor connecting the photovoltaic array and load. The CVT method can't guarantee that the output power is on the maximum power point; it can only keep the output power around the maximum power point. In order to optimize the tracking performance of photovoltaic array, the conductance increment method is utilized to further improve the maximum power point tracking on the basis of using the CVT method. It is different from the traditional conductance increment method when the external environment is constantly changing. The output value is stabilized at a fixed value and the stability around the maximum power point is regarded as the main control target. The iterative length is selected according to the stability of the maximum power point. In this way, it can reach the purpose of eliminating the power oscillation at the maximum power point. The improved control flow chart of the conduct increment method is as shown in Fig.4. $\mathrm{V}_{\mathrm{K}}$ and $\mathrm{I}_{\mathrm{K}}$ are separately the output voltage and current of photovoltaic array at the time of $\mathrm{K}[10-11]$. 


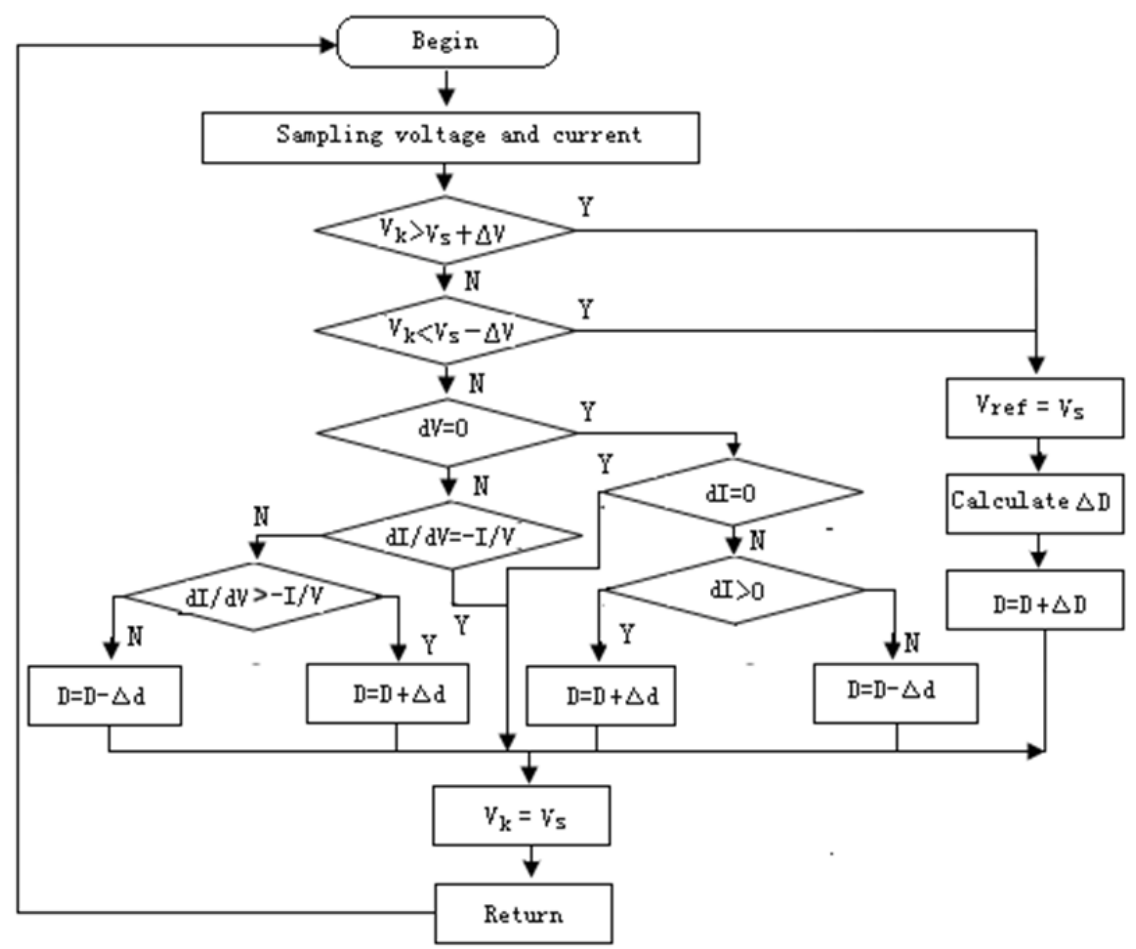

Figure 4. Flow chart with improved conductance increment method

The output status of system is decided by the output voltage $\mathrm{V}_{\mathrm{K}}$ :

(1) When the output voltage $V_{K}$ of photovoltaic array is beyond the range of $V_{S} \pm \Delta V$, stabilize the output voltage in this range in the CVT method;

(2) When the output voltage $V_{K}$ of photovoltaic array is in the range of $V_{S} \pm \Delta V$, implement the maximum power point tacking in the conduct increment method;

(3) Continue adjust the maximum power point until $\mathrm{dI} / \mathrm{dV}=-\mathrm{I} / \mathrm{V}$, at this time, the working point is the maximum power point.

\section{Simulation}

Modelling and simulation were implemented to the Boost DC /DC convertor with matlab simulink. The improved method and the traditional conductance increment method were separately applied to control the system. Simulation curves by using the traditional electric incremental method and improved electric incremental method are shown in Fig.5 and Fig.6.The simulation result shows that under the circumstance when the external environment is changing, the improved method makes the photovoltaic array track the maximum power point more quickly and precisely under the premise that the system stability is guaranteed [12-13]. 

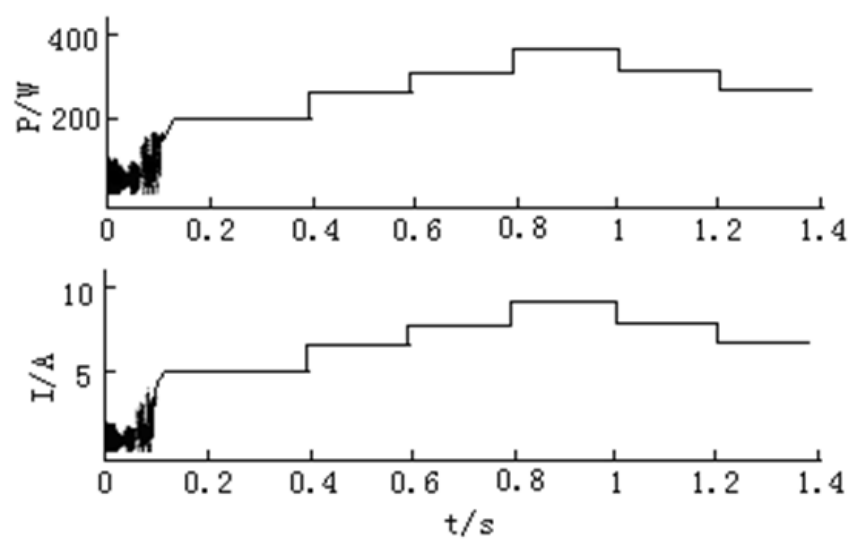

Figure 5. Simulation curve by using the traditional electric incremental method
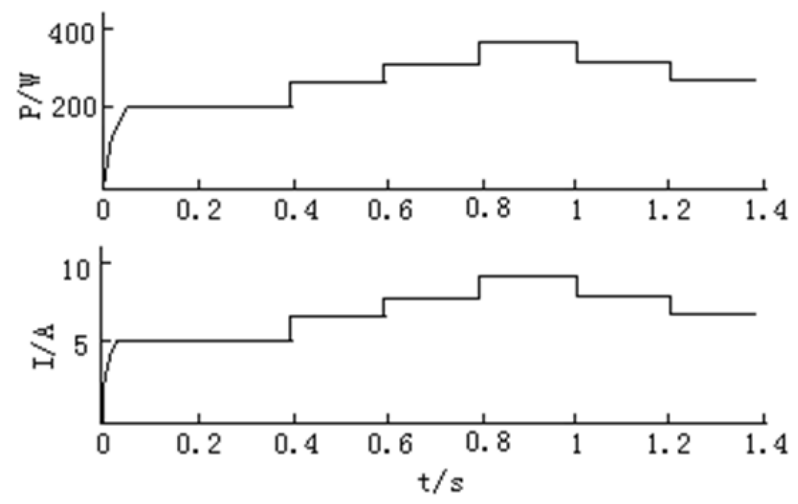

Figure 6. Simulation curve by using improved electric incremental method

From Fig.5 and Fig.6, it can be seem that the improved conductance increment algorithm based on the CVT method can quickly track the weather variations and effectively control the oscillation at the maximum power point. Comparing with the traditional conductance increment method, it has a great superiority and effectively improves the stability precision and the dynamic property of system. The simulation result verified the effectiveness of this conductance increment method. From the simulation result and experimental result, it shows that under the control of this algorithm, the system can stably and quickly track the maximum power point, and the result is high in tracking precision. Under various situations, especially the adverse situation in which the sunlight changes suddenly and so on, it has high adaptive ability and can realize the maximum power point tracking to the photovoltaic cell [14].

\section{Conclusions}

In this article, the improved conductance increment algorithm was adopted to study the tracking of the maximum power point of photovoltaic cell, and the system performance was verified based on the experiment. The tracking speed is fast in the conductance increment algorithm. Under the situation that the external environment is relatively stable, the system owns good stability and can stably work at the maximum power point. When the external environment changes suddenly, the system can also quickly and precisely track the maximum power point and basically eliminate the phenomenon that the system oscillates at the maximum power point at the same time. It is a kind of relatively ideal control method. 


\section{Acknowledgements}

This work is supported by scientific research funded project of Science Technology Department of Zhejiang Province (2015C31128).

\section{References}

1. X.Q Hou, Y.X. Gao.Instrumentation Technology, 4 (2016)

2. V.H Krishnamurthy. IEEE Sustainable Energy, 2, 491(2014)

3. E.M. Ahmed. IEEE Ninth International Conference on Power Electronics and Electronics and Drive Systems, 3, 889(2015)

4. Q.X Yang, Q Wang. The International Conference on Intelligent Human-Machine Systems and Cybernetics, 15, 285(2015)

5. Weiming Shao, Shuying Chen. Journal of Power Supply, 14, 67(2016).

6. P .Rena, V.Darne. Journal of Power Sources, 84, 89(2013)

7. J.W. Dixon, M.E Oriuzar.IEEE Aerospace and Electronic Systems Magazine, 17, 16(2014)

8. L. T. Luca. Propulsion physics (EDP Sciences, Les Ulis, 2009)

9. E.J Cegnar, H.L Hess. Nineteenth Annual IEEE Applied Power Electronics Conference and Exposition, 2, 1160(2004)

10. Qiuxia Yang,Haichen Wang. Chinese Journal of Power Sources, 40, 90(2016)

11. Yaru Zhang ; Chuncheng Han; Journal of Chinese Agricultural Mechanization, 6, 77(2015)

12. Y.P An, J.N Liu. Application of Electronic Technique, 3, 114(2015)

13. Feng Xu.Process Automation Instrumentation, 6, 82(2014)

14. Y.J Do, H.K Young.Journal of Power Sources, 114, 25(2013) 